\title{
Using Thermodynamic Degradation Approach to Quantify Human Stress Response
}

\author{
Satish Boregowda, ${ }^{1}$ Rod Handy, ${ }^{2}$ Darrah Sleeth, ${ }^{2}$ and Naomi Riches ${ }^{2}$ \\ ${ }^{1}$ School of Mechanical Engineering, Purdue University, West Lafayette, IN 47907, USA \\ ${ }^{2}$ Department of Family \& Preventive Medicine, University of Utah, Salt Lake City, UT 84108, USA \\ Correspondence should be addressed to Rod Handy; rod.handy@hsc.utah.edu
}

Received 4 May 2017; Accepted 10 August 2017; Published 11 September 2017

Academic Editor: Angelo Maiorino

Copyright (c) 2017 Satish Boregowda et al. This is an open access article distributed under the Creative Commons Attribution License, which permits unrestricted use, distribution, and reproduction in any medium, provided the original work is properly cited.

\begin{abstract}
The present study provides a thermodynamic degradation approach to model human stress response. Finger skin temperature was used as an indicator of stress response to a stressor (or stressful event) followed by a recovery. The entropy change $(\Delta S)$ is calculated using heat transfer $(\delta Q)$ from the peripheral skin and finger skin temperature $\left(T_{f}\right)$. It was hypothesized that the human stress response, as evidenced by finger skin temperature change, is a quasi-static process. The entropy approach is demonstrated using data from a medical school experimental study. The finger skin temperature was measured under three conditions (relaxation, stressor task, and recovery) during the physiological test profile. The entropy change $(\Delta S)$ is postulated as entropy damage $\left(\Delta S_{\mathrm{D}}\right)$, which is a metric for measuring the aging or system degradation. The aging-ratio, $A_{\text {aging-ratio }}$, that is, the ratio of entropy change due to stressor to that of recovery, is presented for both male and female subjects. The statistical $t$-tests demonstrate statistical significance in human stress response to stressor and recovery states within and between male and female subjects. This novel approach could be valuable to medical researchers, particularly in the field of occupational health to evaluate human exposure to stressful environments.
\end{abstract}

\section{Introduction}

Numerous researchers have been studying human stress physiology to better understand the complexity of stress response to stressful events in different environments. The human physiological system maintains internal core temperature $\left(98.6^{\circ} \mathrm{F}\right)$ at a normal level by enhancing or inhibiting heat production and heat loss. The state of maintaining constant internal temperature is called homeothermic state and the phenomenon is called homeostasis. The finger skin temperature, which is considered to be representative of the sympathetic nervous system (SNS), is a strong indicator of human stress response [1]. Thermoreceptors located underneath the skin respond to both local temperature and its changes. Signals from the thermoreceptors are transmitted by the central nervous system to the hypothalamus which in turn determines the overall thermal state of the body and issues the appropriate effector commands, which cause changes in the body temperature via blood flow changes and metabolic heat production.
The leading stress researcher Selye [2] defined stress as the nonspecific response of the body to any demand. In other words, he established the fact that stress response to a stressor is wear and tear of the body. Karwowski [3] has clearly elucidated the importance of using psychophysiological measures to quantify mental stress, fatigue, and performance in the field of human factors and ergonomics. Mental stresses cause a wide range of effects on worker performance. As discussed by A. Mital and C. Mital [4], these could be physiological (elevated heart rate, blood pressure, etc.), performance related (decreased output, increased errors, etc.), or behavioral (lack of attention, anxiety, etc.). Several researchers have investigated the effects of mental and physical stresses. Increase in heart rates [5-7], changes in blood pressure [8], and body temperature [9] are some of the human stress responses used in the past. Another study by Boregowda et al. [1012] investigated the use of thermodynamics-based Maxwell relations $[13,14]$ to quantify stress response in terms of multiple physiological variables (blood pressure, heart rate, skin temperature, electromyogram, and skin conductance level). 
However, none of these studies use an easily measurable physiological indicator and a straightforward thermodynamicsbased methodology. The present study overcomes the past limitations to quantify stress response using an easily measurable finger skin temperature in a straightforward thermodynamic expression for entropy change. This study, which used specific event data, is unique in that it examines entropy change as a measure of reliability, based on the thermodynamic degradation science perspective [15]. The thermodynamics-based approach was verified using data from an experimental study conducted at the Eastern Virginia Medical School (EVMS). The formulations of entropy change $(\Delta S)$, postulated entropy damage $\left(\Delta S_{\text {damage }}\right)$, and aging-ratio ( $\left.A_{\text {aging-ratio }}\right)$ are provided in the next section.

\section{Modeling and Formulation}

2.1. Entropy Change Formulation. Consider a quasi-static process of heat transfer taking place between the human physiological system and the physical environment as a result of a stressful event. This would be reflected in changes to the finger skin temperature $\left(T_{f}\right)$. The transfer of heat $(\delta Q)$ or entropy transfer $\left(\delta Q / T_{f}\right)$ takes place via finger skin with the finger skin temperature $\left(T_{f}\right)$ as the boundary temperature. The entropy change is therefore given by (1) as defined in [15]:

$$
\Delta S=\int_{1}^{2} \frac{\delta Q}{T_{f}}=m C_{P} \ln \left(\frac{T_{f 2}}{T_{f 1}}\right),
$$

where $\Delta S$ is entropy change from State 1 to State $2, \delta Q$ is heat transfer from the human system to the environment, $T_{f}$ is finger skin temperature $(\mathrm{K}), m$ is human body mass (or weight) in $\mathrm{kg}$, and $C_{P}$ is specific heat of the human body = $3.5 \mathrm{~kJ} / \mathrm{kg} \cdot \mathrm{K}$.

2.2. Entropy Damage Formulation. The deviation from the human physiological system's relaxed state is characterized by changes in the body's relaxed state, which may be positive or negative, depending on the imposed external stressor and the internal physiological condition. Specifically, physiological entropy is qualitatively defined as a measure of disorder [16]. It is a kind of global measure that specifies how violent motions and reactions are occurring in nature. Hence, the entropy change in the human physiological system shows the extent of activity within the body as a whole; thus, the entropy change is a significant quantity that characterizes the human body from both thermodynamic and holistic (i.e., considering a human body as a whole) viewpoints.

Postulate 1 (entropy damage). The entropy change $(\Delta S)$ is a measure of disorder in the human physiological system caused by heat transfer due to imbalance in the internal physiology as a result of imposed psychological stress and is equated to entropy damage $\left(\Delta S_{\mathrm{D}}\right)$.

$$
\Delta S=\Delta S_{\mathrm{D}}=\int_{1}^{2} \frac{\delta Q}{T_{f}}=m C_{P} \ln \left(\frac{T_{f 2}}{T_{f 1}}\right) .
$$

The entropy damage during the quasi-static physiological process shall be used to compute the aging-ratio [14] and is presented in the next subsection.
2.3. Aging-Ratio Formulation. Consider a quasi-static process involving human stress response to a stressful task followed by a recovery. The data is collected at three different states: (1) relaxation; (2) stressor task; and (3) recovery. The relaxation state is considered as the reference state and any deviation from it is measured in terms of entropy damage.

Postulate 2 (aging-ratio $\left.\left(A_{\text {aging-ratio }}\right)\right)$. The ratio of entropy damage from relaxation (State 1) to stressor task (State 2) relative to the entropy damage during the process from relaxation (State 1 ) to recovery (State 3 ) is termed as agingratio.

$$
A_{\text {aging-ratio }}=\frac{\left(\Delta S_{\mathrm{D}}\right)_{\text {stressor }}}{\left(\Delta S_{\mathrm{D}}\right)_{\text {recovery }}}=\frac{\ln \left(T_{f 2} / T_{f 1}\right)}{\ln \left(T_{f 3} / T_{f 1}\right)},
$$

where $T_{f 1}$ is finger skin temperature at the end of relaxation period. $T_{f 2}$ is finger skin temperature at the end of stressor period. $T_{f 3}$ is finger skin temperature at the end of recovery period.

The aging-ratio adopted from [15] provides a quantitative measure of human physiological aging or system degradation.

\section{Methodology}

3.1. Subjects. Forty-eight male (48) medical residents aged 22-40 years and weighing 57-106 kg and thirty-six (36) female medical residents aged 23-41 years and weighing $48-114 \mathrm{~kg}$ participated in the study. All the eight-four (84) subjects completed a standard physiological stress profile procedure routinely used for clinical assessment in the Primary Care Medicine Department at Eastern Virginia Medical School.

3.2. Data Collection. The physiological data were collected by a ProComp+ biofeedback system connected to a Dell $166 \mathrm{MHz}$ PC computer running a MultiTrace biofeedback software for data processing and analysis, as well as a standalone Dinamap 1846 Vital Signs Monitor (Critikon Inc., Tampa, FL). The stress profile (Stroop test) is a 20-minute standard testing sequence, during which skin temperature from the palmar surface of the left hand little finger is collected continually during the three states identified previously, specifically.

State 1 (relaxation period). It includes relaxing in a semireclining position with eyes open for three minutes followed by relaxing with eyes closed for three minutes (total time $=6$ minutes).

State 2 (stressor period). This includes solving a series of forty (40) six-second long cognitive tasks presented on a computer screen, that is, Stroops-type color-naming tasks and arithmetic problems, which are alternated. The sequence of tasks is the same for all subjects (total time $=8$ minutes).

State 3 (recovery period). This includes relaxing again with eyes open for three minutes followed by relaxing with the eyes closed for three minutes (total time $=6$ minutes). 
TABLE 1: Mean finger skin temperature change within male and female subjects at stressor and recovery states.

\begin{tabular}{|c|c|c|c|c|}
\hline Response & Sex & State & Mean change (from relaxation State 1) & Significance $(p)$ \\
\hline \multirow{4}{*}{ Finger skin temperature $\left(T_{f}\right)$ in $\mathrm{K}$} & \multirow{2}{*}{$\mathrm{M}$} & 2 (stressor) & -1.37 & 0.00 \\
\hline & & 3 (recovery) & -0.87 & 0.00 \\
\hline & \multirow{2}{*}{$\mathrm{F}$} & 2 (stressor) & -0.57 & 0.03 \\
\hline & & 3 (recovery) & -0.34 & 0.10 \\
\hline
\end{tabular}

Using the finger cuff, the finger skin temperature was recorded after State 1 (relaxation period), State 2 (stressor period), and State 3 (recovery period).

3.3. Illustrative Example. Let us consider one of the subjects with following data points:

$$
\begin{aligned}
& m=75.3 \mathrm{~kg} \\
& C_{P}=3.5 \mathrm{~kJ} / \mathrm{kg} \cdot \mathrm{K} \\
& T_{f 1}=\text { finger skin temperature at the end of relaxation } \\
& \text { period }=305.75 \mathrm{~K} \\
& T_{f 2}=\text { finger skin temperature at the end of stressor } \\
& \text { period }=305.39 \mathrm{~K} \\
& T_{f 3}=\text { finger skin temperature at the end of recovery } \\
& \text { period }=305.07 \mathrm{~K} \\
& \Delta S_{\mathrm{DS}}=\text { entropy damage at stressor State } 2 \\
& \Delta S_{\mathrm{DR}}=\text { entropy damage at recovery State } 3
\end{aligned}
$$

For the process from State 1 (relaxation) to State 2 (stressor task), the entropy damage is given by

$$
\begin{aligned}
\Delta S_{\mathrm{DS}} & =m C_{P} \ln \left(\frac{T_{f 2}}{T_{f 1}}\right) \\
& =(75.3 \mathrm{~kg}) *(3.5 \mathrm{~kJ} / \mathrm{kg} \cdot \mathrm{K}) * \ln \left(\frac{305.39 \mathrm{~K}}{305.75 \mathrm{~K}}\right) \\
& =-\mathbf{0 . 3 1} .
\end{aligned}
$$

For the process from State 1 (relaxation) to State 3 (recovery), the entropy damage is given by

$$
\begin{aligned}
\Delta S_{\mathrm{DR}} & =m C_{P} \ln \left(\frac{T_{f 3}}{T_{f 1}}\right) \\
& =(75.3 \mathrm{~kg}) *(3.5 \mathrm{~kJ} / \mathrm{kg} \cdot \mathrm{K}) * \ln \left(\frac{305.07 \mathrm{~K}}{305.75 \mathrm{~K}}\right) \\
& =-\mathbf{0 . 5 8} .
\end{aligned}
$$

The negative sign indicates the entropy damage takes place with heat loss occurring from the body to the environment with the decrease of finger skin temperature reflecting stress response.

The aging-ratio is calculated accordingly:

$$
A_{\text {aging-ratio }}=\frac{\Delta S_{\mathrm{DS}}}{\Delta S_{\mathrm{DR}}}=\frac{\ln \left(T_{f 2} / T_{f 1}\right)}{\ln \left(T_{f 3} / T_{f 1}\right)}=\frac{-0.31}{-0.58}=\mathbf{0 . 5 3} \text {. }
$$

The aging-ratio gives a quantitative measure of wear and tear resulting in aging or system degradation. More detailed results and analysis are provided in the next section.

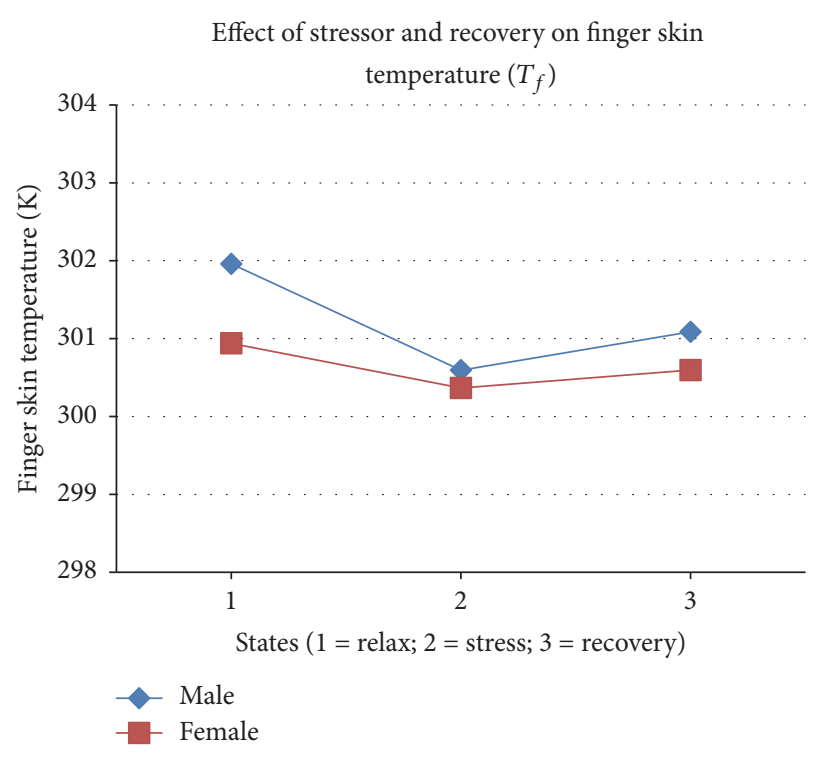

FIGURE 1: Finger skin temperature variation in male and female subjects.

3.4. Statistical Tests. The following $t$-tests, at the level of significance, $\alpha=0.05$, are conducted.

(a) $t$-tests: they include tests with two paired samples for means.

A single-tailed $t$-test with paired two samples is conducted to determine if there is a difference in mean physiological stress response (finger skin temperature and entropy damage) for both male and female subjects at stressor and recovery states relative to the relaxation (reference) state.

(b) $t$-tests: they include tests with two samples assuming unequal variances.

A single-tailed $t$-test with two independent samples is conducted to determine if there is any significant difference between male and female mean stress responses (finger skin temperature, entropy damage, and aging-ratio) for both stressor and recovery states relative to the relaxation (reference) state.

\section{Results and Analysis}

The mean change in finger skin temperature from relaxation State 1 to stressor State 2 and recovery State 3 for both male and female subjects is provided in Figure 1. The $t$-test on paired samples for male and female subjects is provided in Table 1. It is clear from Table 1 that there is a significant statistical difference in the mean finger skin temperature change from relaxed (reference) State 1 to that of stressor 
TABLE 2: Mean entropy damage values within male and female subjects at stressor and recovery states.

\begin{tabular}{lcccc}
\hline Response & Sex & State & $\begin{array}{c}\text { Mean change in response } \\
\text { (from relaxation State 1) }\end{array}$ & Significance $(p)$ \\
\hline \multirow{2}{*}{ Entropy damage } & $\mathrm{M}$ & 2 (stressor) & -1.11 & 0.00 \\
& & 3 (recovery) & -0.76 & -0.41 \\
& $\mathrm{~F}$ & 2 (stressor) & -0.24 & 0.09 \\
\hline
\end{tabular}

TABLE 3: Testing differences between male and female stress responses.

\begin{tabular}{lccc}
\hline Response & Mean change in response from relaxation State 1 & Female & Significance $(p)$ \\
& Male & -0.57 & 0.01 \\
Finger skin temperature at stressor State 2 & -1.37 & -0.34 & 0.07 \\
Finger skin temperature at stressor State 3 & -0.87 & -0.41 & 0.02 \\
Entropy damage at stressor State 2 & -1.19 & -0.24 & 0.03 \\
Entropy damage at stressor State 3 & -0.76 & 1.14 & 0.21 \\
Aging-ratio & 0.73 & & \\
\hline
\end{tabular}

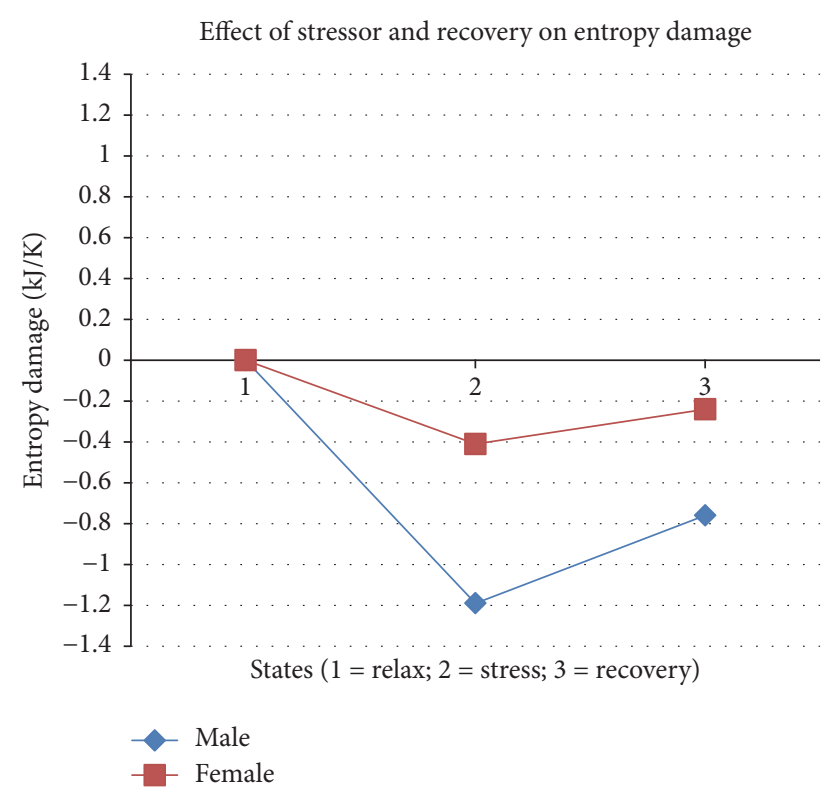

FIGURE 2: Entropy damage variation in male and female subjects.

(State 2) and recovery (State 3) for male subjects. However, in female subjects it is observed that there is statistical significance in the mean finger skin temperature change from relaxed State 1 to stressor State 2 while there is no statistical difference between relaxed and recovery states. The entropy damage occurs when there is a change from relaxation State 1 to stressor State 2 and recovery State 3. This takes us to the next step to quantitatively demonstrate entropy damage for both males and females at stressor and recovery states.

Figure 2 shows the entropy damage for both male and female subjects. Relaxation State 1 is the reference state and has a zero value of entropy damage. Any change from this reference state is shown in Figure 2 and statistical differences are indicated in Table 2 for both male and female subjects. It is clear from Table 2 that there is a significant difference

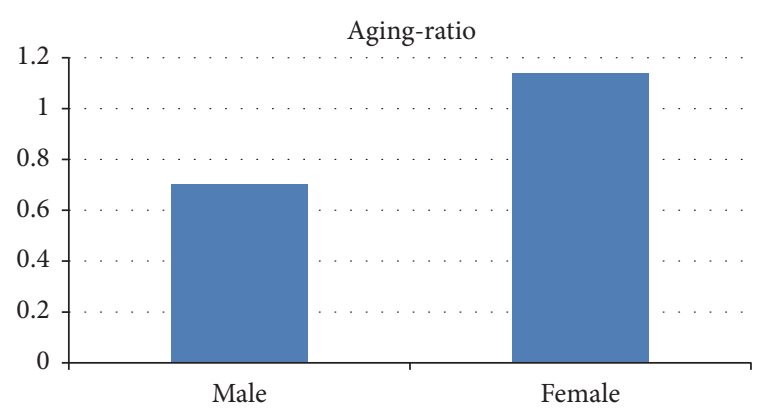

Figure 3: Aging-ratio for male and female subjects.

between entropy damage values at the stressor and recovery states for male subjects. At level of significance, $\alpha=0.05$, the entropy damage for female subjects is not that significant as indicated by a $p$ value of 0.09 in Table 2 .

The negative values of entropy damage indicate that the heat is lost from the body with decrease in finger skin temperature during the stressor task [1]. The ratio of entropy damage at the stressor state $\left(\Delta S_{\mathrm{DS}}\right)$ relative to the recovery state $\left(\Delta S_{\mathrm{DR}}\right)$ is termed as aging-ratio $\left(A_{\text {Aging-Ratio }}\right)$ [15].

The statistical $t$-tests for two independent samples of male $(n=48)$ and female $(n=36)$ subjects assuming unequal variances are presented in Table 3 . At level of significance, $\alpha$ $=0.05$, there is significant statistical difference between male and female subjects in terms of finger skin temperature (at stressor State 2) and entropy damage (at stressor State 2 and recovery State 3 ). However, with a $p$ value of 0.07 , there is no evidence to indicate that there is significant difference in the values of finger skin temperature (at stressor State 2) between male and female subjects.

The difference in aging-ratio for male and female subjects is shown in Figure 3. Further from Table 3, it is clear that there is no significant difference between the male and female aging-ratio. The aging-ratio is an indication of wear and tear over a period of time. The $t$-test results presented in Table 3 serve to evaluate if there are any significant differences 
between male and female subjects pertaining to the values of finger skin temperature, entropy damage, and aging-ratio.

\section{Conclusion}

This study involved the use of entropy change expression to evaluate human stress response under the framework of thermodynamic degradation methodology [15]. It was postulated that entropy change is simply entropy damage expressed in terms of finger skin temperature. The aging-ratio is obtained from the ratio of entropy damage during a stressful task relative to that of a recovery period. Detailed statistical results involving data from an experimental study using eightyfour (84) subjects are presented. The $t$-tests indicate that the entropy damage and aging-ratio provide valuable metrics with which to evaluate human stress response. In particular, this thermodynamic degradation approach could be used in occupational settings where workers are exposed to various environmental stressors.

\section{Conflicts of Interest}

The authors declare that there are no conflicts of interest regarding the publication of this paper.

\section{Acknowledgments}

The authors wish to thank Dr. Olafur S. Palsson and Ms. Brenda Downing from Eastern Virginia Medical School and Dr. Alan Pope of NASA Langley Research Center for supporting this research project.

\section{References}

[1] J. L. Andreassi, Psychophysiology: Human Behavior and Physiological Stress Response, Lawrence Erlbaum Associates, Mahwah, NJ, USA, 4th edition, 2007.

[2] H. Selye, The Stress of Life, McGraw-Hill, New York, NY, USA, 1984.

[3] W. Karwowski, "The discipline of human factors and ergonomics," in Handbook of Human Factors and Ergonomics, G. Salvendy, Ed., pp. 1-37, John Wiley \& Sons, New York, NY, USA, 4th edition, 2012.

[4] A. Mital and C. Mital, "Mental stress and physiological responses," Trends in Ergonomics/Human Factors I, pp. 353-358, 1984.

[5] E. P. Grandjean, G. Wotzka, R. Schaad, and A. Gilgen, "Fatigue and stress in air traffic controllers," Ergonomics, vol. 14, no. 1, pp. 159-165, 1971.

[6] H. J. G. Zwaga, "Psychophysiological Reactions to Mental Tasks: Effort or Stress?” Ergonomics, vol. 16, no. 1, pp. 61-67, 1973.

[7] R. J. Barnard and H. W. Duncan, "Heart rate and ecg responses of fire fighters," Journal of Occupational Medicine, vol. 17, no. 4, pp. 247-250, 1975.

[8] S. V. Kasl and S. Cobb, "Blood pressure changes in men undergoing job loss: a preliminary report.," Psychosomatic Medicine, vol. 32, no. 1, pp. 19-38, 1970.

[9] T. Renbourne, "Psycho-physiological stress and the soldier, with a review of the literature," US Army Soldier Clothing and Equipment Physiological Research Establishment 118, 1961.
[10] S. C. Boregowda, S. N. Tiwari, S. K. Chaturvedi, and D. R. Redondo, "Analysis and quantification of mental stress and fatigue using Maxwell relations from thermodynamics," Journal of Human Ergology, vol. 26, no. 1, pp. 7-16, 1997.

[11] S. C. Boregowda and W. Karwowski, "Modeling of human physiological stresses: a thermodynamics-based approach," Occupational Ergonomics, vol. 5, no. 4, pp. 235-248, 2005.

[12] S. Boregowda, R. Handy, D. Sleeth, and A. Merryweather, "Measuring Entropy Change in a Human Physiological System," Journal of Thermodynamics, vol. 2016, Article ID 4932710, 2016.

[13] H. B. Callen, Thermodynamics and An Introduction to Thermostatics, John Wiley \& Sons, New York, NY, USA, 1985.

[14] Y. Cengel and M. Boles, Thermodynamic: An Engineering Approach, McGraw-Hill, New York, NY, USA, 2006.

[15] A. Feinberg, Thermodynamic Degradation Science, John Wiley \& Sons, New York, NY, USA, 2016.

[16] I. Aoki, "Entropy flow and entropy production in the human body in basal conditions," Journal of Theoretical Biology, vol. 141, no. 1, pp. 11-21, 1989. 

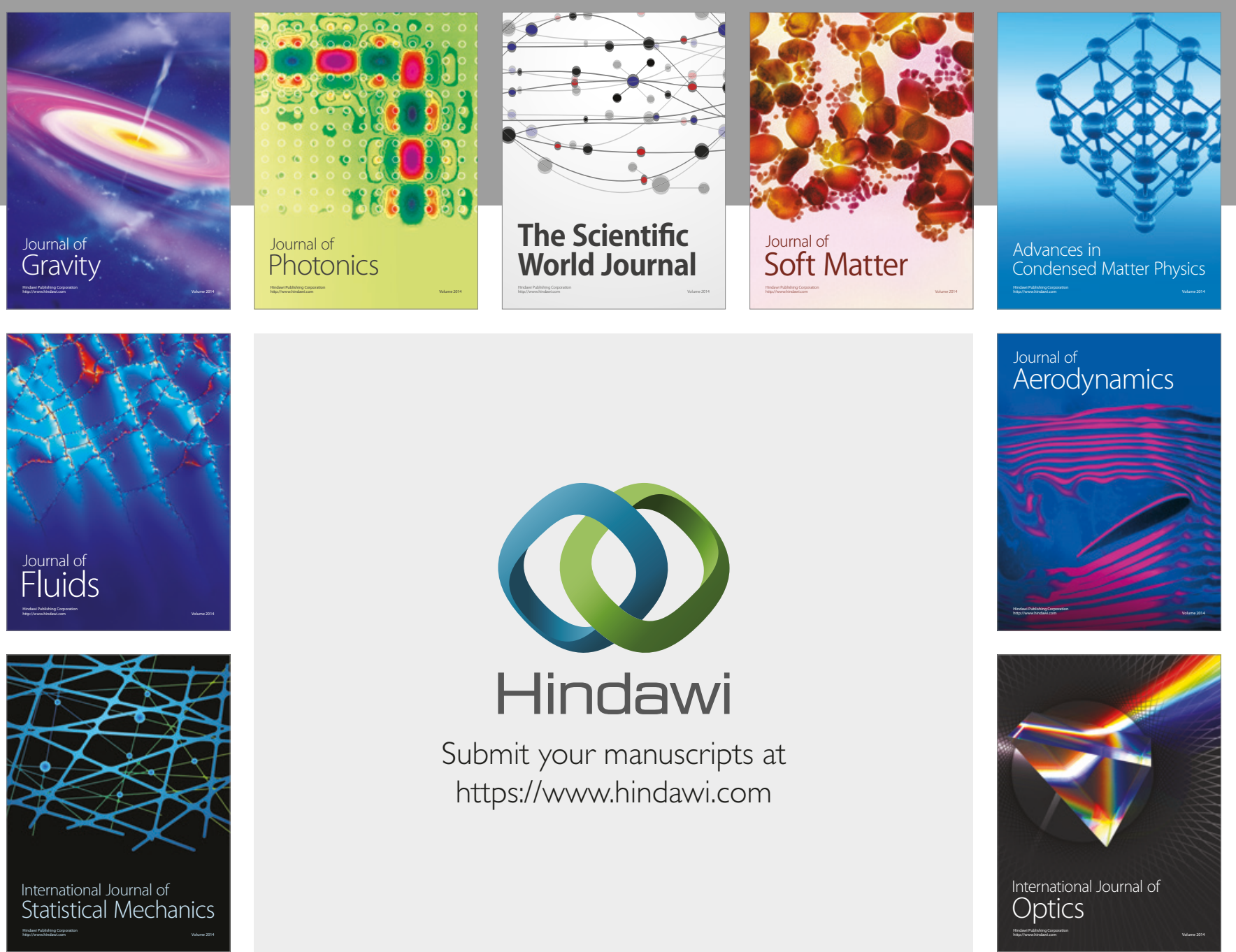

Submit your manuscripts at

https://www.hindawi.com
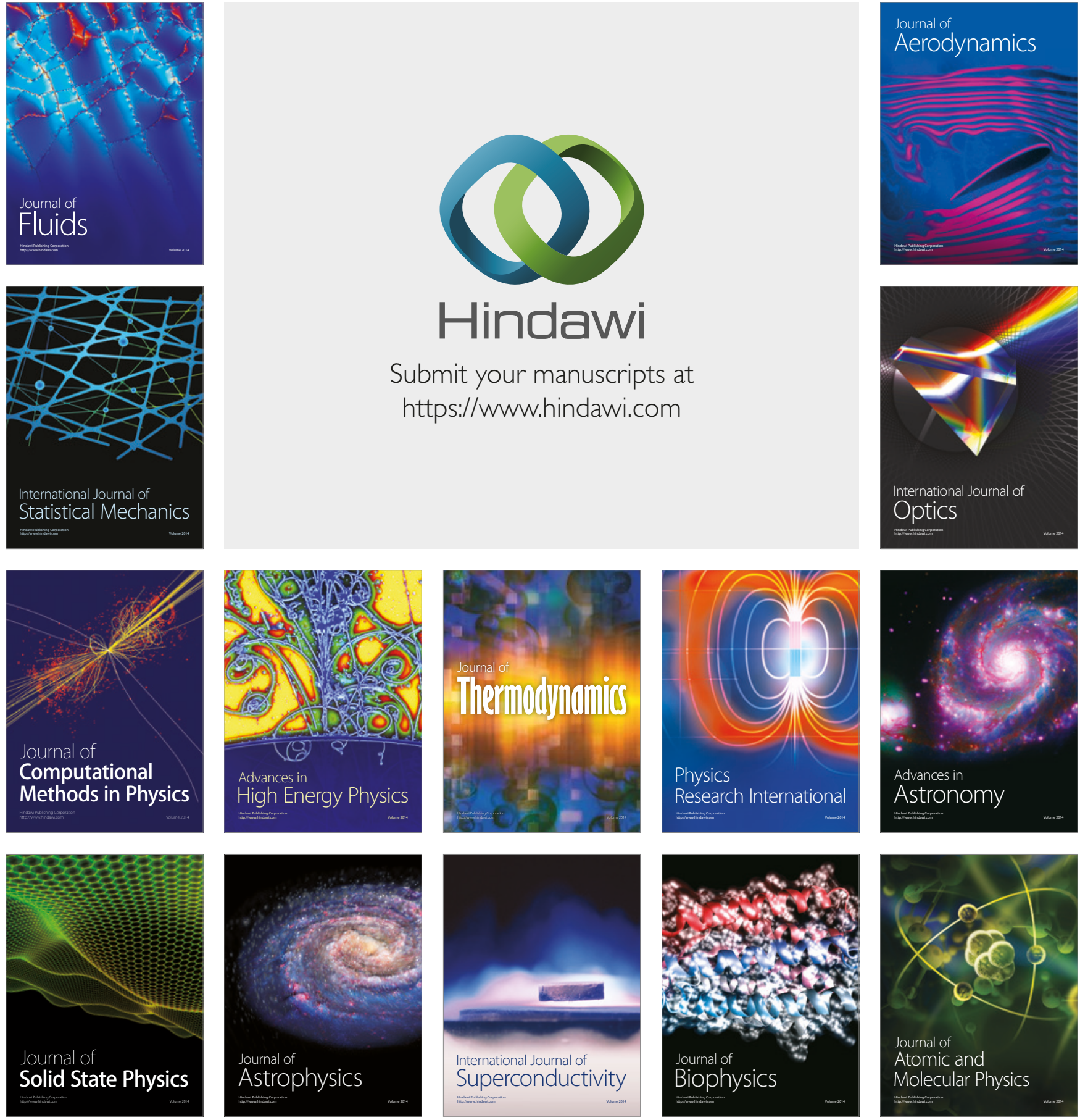